\title{
The testing of the tensil strenght concrete at bending
}

\section{Novica Toncev}

\begin{abstract}
The theme of this paper is the behavior analysis of the concrete girders classically armored with the addition of mineral wool fibers.

The author made five sets of concrete girders of the same geometric characteristics: $12 \times 20 \times 250 \mathrm{~cm}$ and twelve concrete elements (cubes and prisms).

The following parameters were tested: the strength of the classically armored concrete with the addition of mineral wool fibers, the concrete ductility and the control of cracking.

The girders were loaded with the variable force: $2 \times 5 \mathrm{kN}$ to $2 \times 19 \mathrm{kN}$ at the short time load after 28 days from the day of their making and at the long time load, during 365 days.

The influence of the concrete, armored by the fibers mineral wool, reflected to the concrete strength at bending $16,5 \%$.

Key words: mineral wool fibers, shrinkage, creeping, cracks, ductility, tensile strength at bending.
\end{abstract}

\section{INTRODUCTION}

The need for the concrete better mechanical characteristics follows the building operations from the moment from their application up to now.

There are some data that the Romans managed to make the concrete with better characteristics by adding some fibers to the concrete paste.

The theme of many researches was the idea to get the concrete with better characteristics by adding different material fibers (steel, polypropylene, optic, texstily, fibers). That concrete was better than the traditional type of concrete. It's quality remained the inspiration and the need of many investigators and constructors.

\section{RESEARCH SIGNIFICANCE}

The aim of this paper is to show the influence of material fibers on the behavior of the reinforced concrete elements (supports and samples) exposed to bending by the shearing force. Research aspects enclude the tensile strength, the ductility and the control cracking.

\section{EXPERIMENTAL PROGRAM}

This paper describes the behavior of the concrete reinforced girders with or without were the additional of the fibers and 12 concret speciments (three cubes and nine prisms loadedand unloaded.

The concrete mix design is as follows there aggregate fractions (South Morava): $35 \%$ of $0-4$ $\mathrm{mm}, 25 \%$ of $4-8 \mathrm{~mm}, 40 \% 8-16 \mathrm{~mm}, 300 \mathrm{~kg} / \mathrm{m}^{3}$ of Portland cement from (Greece) and w/c $-0,55 \%$.

The author made the concrete girders according the program: a set test of girders $12 \times 20 \times 250 \mathrm{~cm}$ armored with $4 \varnothing 8$ of the ribbed armature; $2 \varnothing 6$ smooth armature in the upper girder area (the constructive armature) with three stirrups $3 \varnothing 6$ : one in $1 / 2$ half of the girder span and other the rest above the support each: two sets of girders $12 \times 20 \times 250 \mathrm{~cm}$ classically armored with $4 \varnothing 8$ of the ribbed armature, $2 \varnothing 6$ of the smooth armature in the upper area of the girder with three stirrups $3 \not 66$ one of them in $1 / 2$ of the girder span and one above the girders support each with 100 gr mineral wool fibers.

Another twelve concrete elements were done: three sets of concrete cubes $(15 \times 15 \times 15 \mathrm{~cm}$ each) according to the concrete mix design of the armored girders; three of them were made without the addition of the mineral fibers to define the concrete make; nine concrete prisms $10 \times 10 \times 30 \mathrm{~cm}$ to fallow the concrete shrinkage of 365 day from the day of their making; three concrete prisms $10 \times 10 \times 30 \mathrm{~cm}$ to define the diagram $\sigma-\varepsilon$.

All the concrete girders of the same geometrics were tested at short time load 28 days from the day of their making, and they were tested at long time load 365 days.

All the concrete elements (the girders and the specimen's) were tested by the use of deformeters at the base $21 \mathrm{~cm}$ and accuracy of 1/100 $\mathrm{mm}$.

\section{EXPERIMENTAL PROCESS}

The concrete girders armored according to the procedure were loaded with the fallowing process: from $\mathrm{P}=2 \times 3,5 \mathrm{kN}, 2 \times 5 \mathrm{kN}, 2 \times 6,5 \mathrm{kN}, 2 \times 9,5 \mathrm{kN}$, $2 \times 10,75 \mathrm{kN}, 2 \times 13,0 \mathrm{kN}, 2 \times 14,0 \mathrm{kN}, 2 \times 15,0 \mathrm{kN}$, $2 \times 17,0 \mathrm{kN}$ up to $2 \times 19,0 \mathrm{kN}$ (tab.1) . 


\begin{tabular}{|c|c|c|c||c|c|}
\hline & $\mathrm{P} \mathrm{kN}$ & $\sigma_{\mathrm{br}}$ & $\sigma_{\mathrm{ar}}$ & $\varepsilon_{\mathrm{br}}$ & $\varepsilon_{\mathrm{ar}}$ \\
\hline 1 & 3,5 & 4,64 & 122,78 & $1,47315 \times 10^{-4}$ & $6,13900 \times 10^{-4}$ \\
\hline 2 & 5,0 & 6,42 & 169,00 & $2,03895 \times 10^{-4}$ & $8,45000 \times 10^{-4}$ \\
\hline 3 & 6,25 & 7,86 & 206,82 & $2,48253 \times 10^{-4}$ & $1,03458 \times 10^{-3}$ \\
\hline 4 & 9,25 & 11,44 & 302,47 & $3,63124 \times 10^{-4}$ & $1,51235 \times 10^{-3}$ \\
\hline 5 & 10,75 & 13,21 & 349,34 & $4,21904 \times 10^{-4}$ & $1,74670 \times 10^{-3}$ \\
\hline 6 & 13,0 & 15,82 & 419,65 & $5,03809 \times 10^{-4}$ & $2,09825 \times 10^{-3}$ \\
\hline 7 & 14,0 & 17,05 & 451,04 & $5,41587 \times 10^{-4}$ & $2,25520 \times 10^{-3}$ \\
\hline 8 & 15,5 & 18,75 & 559,27 & $5,81587 \times 10^{-4}$ & $2,69080 \times 10^{-3}$ \\
\hline 9 & 17,5 & 21,18 & 560,28 & $6,72698 \times 10^{-4}$ & $2,80340 \times 10^{-3}$ \\
\hline 10 & 19,0 & 22,96 & 607,15 & $7,28880 \times 10^{-4}$ & $3,03575 \times 10^{-3}$ \\
\hline
\end{tabular}

\begin{tabular}{|c|c||c|c||c|c|}
\hline & $\mathrm{P} \mathrm{kN}$ & $\sigma_{\mathrm{bm}}$ & $\sigma_{\mathrm{am}}$ & $\varepsilon_{\mathrm{bm}}$ & $\varepsilon_{\mathrm{am}}$ \\
\hline 1 & 3,5 & 4,34 & 120,27 & $1,31428 \times 10^{-4}$ & $6,01350 \times 10^{-4}$ \\
\hline 2 & 5,0 & 5,92 & 164,81 & $1,81587 \times 10^{-4}$ & $8,24050 \times 10^{-4}$ \\
\hline 3 & 6,25 & 7,02 & 195,25 & $2,21587 \times 10^{-4}$ & $9,76250 \times 10^{-3}$ \\
\hline 4 & 9,25 & 10,89 & 256,38 & $2,82222 \times 10^{-4}$ & $1,28175 \times 10^{-3}$ \\
\hline 5 & 10,75 & 12,2 & 288,55 & $3,23809 \times 10^{-4}$ & $1,44250 \times 10^{-3}$ \\
\hline 6 & 13,0 & 14,79 & 332,80 & $3,74285 \times 10^{-4}$ & $1,66400 \times 10^{-3}$ \\
\hline 7 & 14,0 & 15,21 & 435,92 & $4,83001 \times 10^{-4}$ & $2,17960 \times 10^{-3}$ \\
\hline 8 & 15,5 & 16,16 & 460,56 & $5,13015 \times 10^{-4}$ & $2,30280010^{-3}$ \\
\hline 9 & 17,5 & 18,15 & 558,15 & $5,76190 \times 10^{-4}$ & $2,79070 \times 10^{-3}$ \\
\hline 10 & 19,0 & 21,84 & 607,15 & $6,93650 \times 10^{-4}$ & $3,03575 \times 10^{-3}$ \\
\hline
\end{tabular}

Tab.1 The calculated and measured values of the stress and the dilatations

The first hardly seen crack (fig.2) appeared in $1 / 2$ at the force of $\mathrm{P}=2 \times 8 \mathrm{kN}$, the second crack was a little bit langer and at the force of $\mathrm{P}=2 \times 10 \mathrm{kN}$.

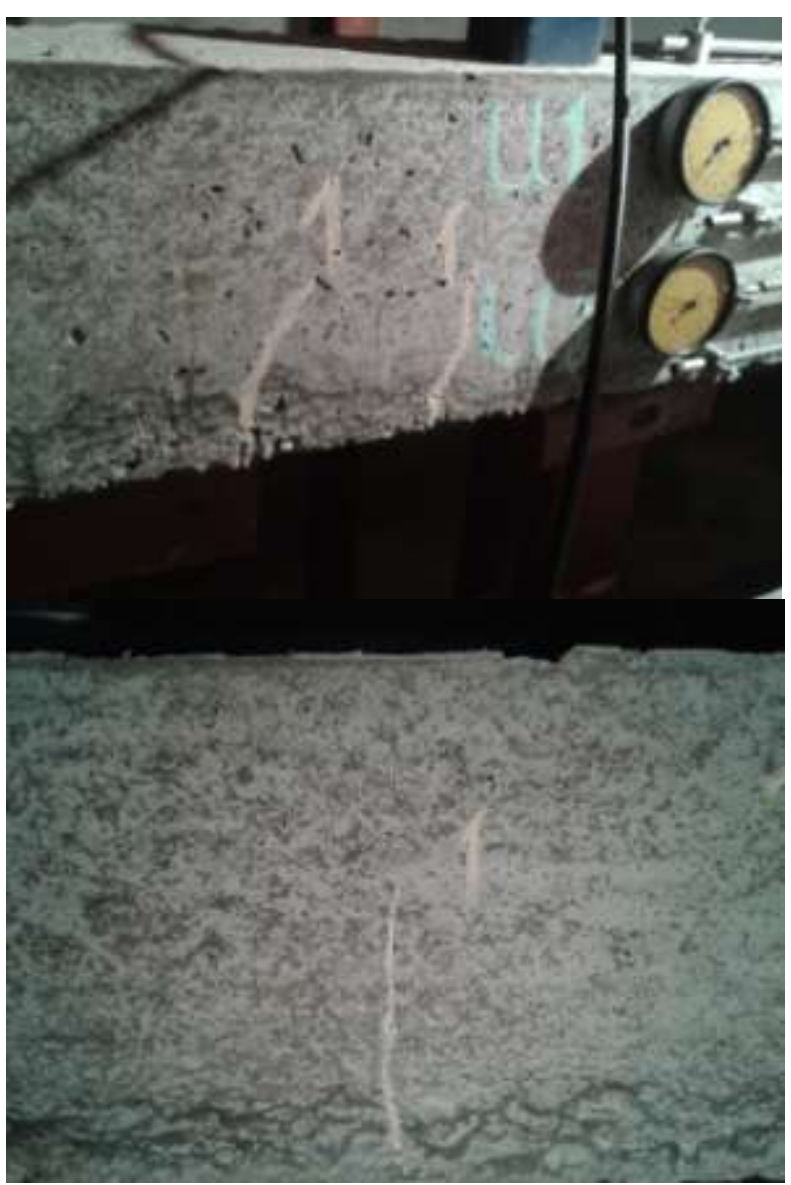

By increasing the load there appeared a number of small cracks, up to the final crack in the cross section in $1 / 2$ with a blunt detonation. (fig 3 ) .

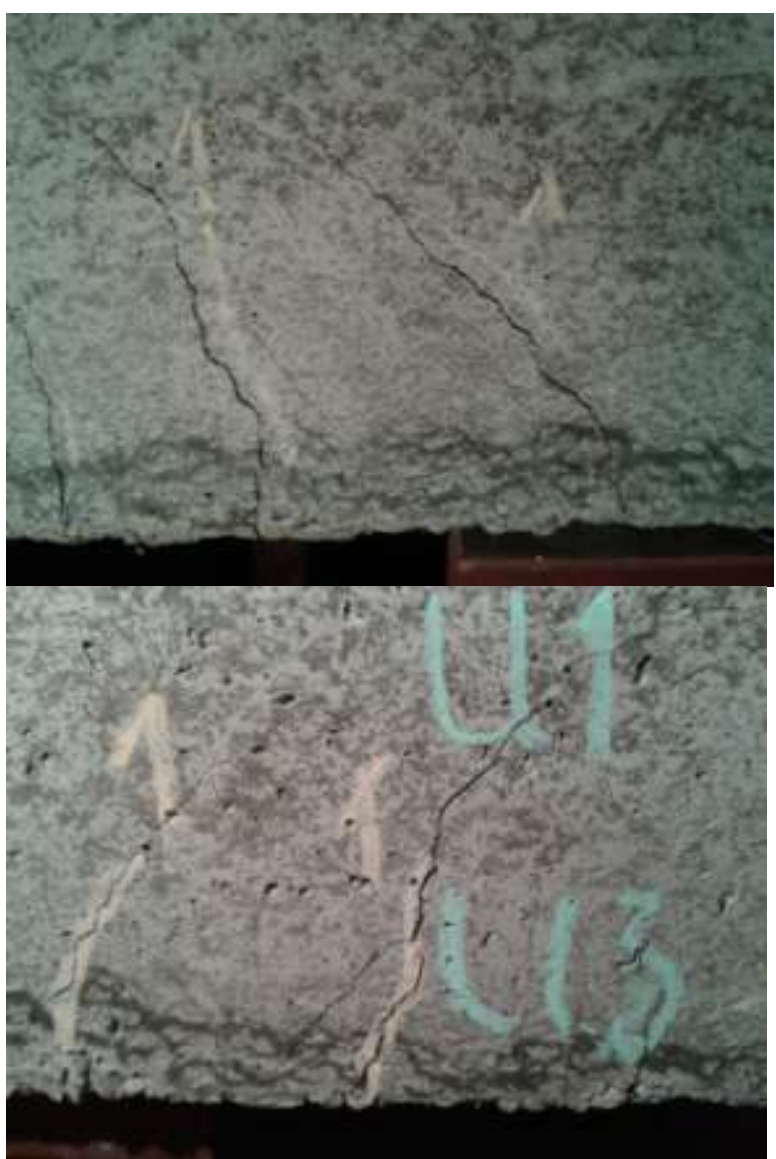

Fig.3 The next crack on fornt and both sides

The dilatations, the stress and the flexions were simultaneously measured by loading the girders. The flexions increased from $2,2 \mathrm{~cm}$ in $1 / 2$ to $2,65,3,02$, 3,05 to $4,00 \mathrm{~cm}$ i.e. at the force of $2 \times 19,0 \mathrm{kN}$ which provoked the cracking (fig.4) .

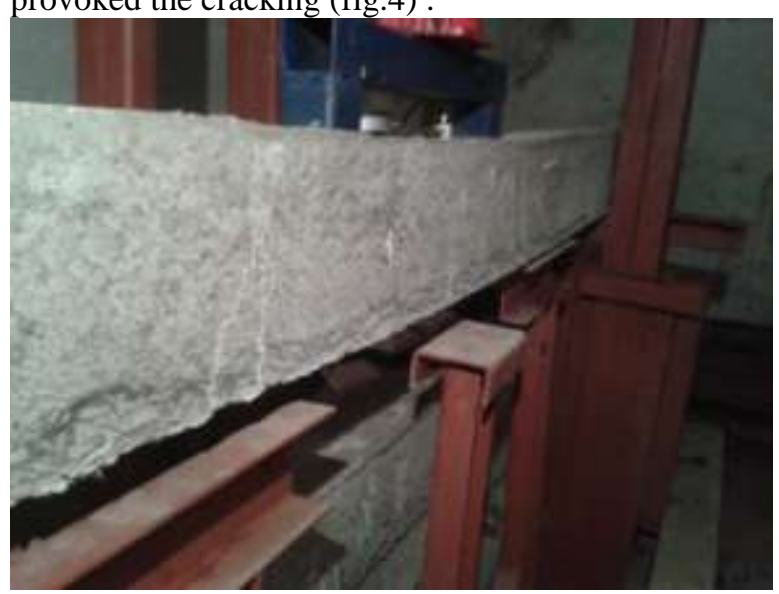

Fig.2 The first crack front and back opposit 


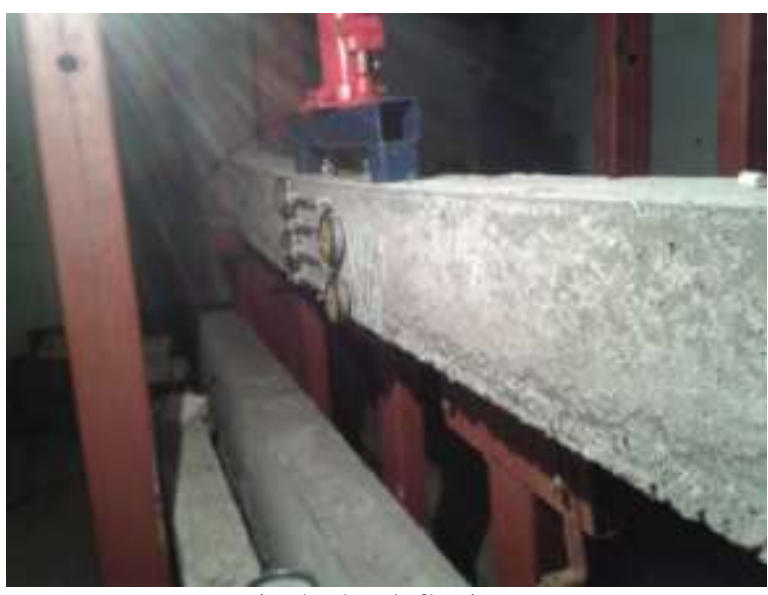

Fig.4 The deflexion

\section{DILATATIONS MEASURING IN THE CONCRETE AND THE ARMATURE}

The dilatations for the acceptance of the bending moment were measured in the tensed armature (of the biggest bending moment) and in the upper pressed girders armature. The chosen arrangement of the measured places enabled to get a more real image of the pressed and the tensed area at the girders and the real values of the stress and the dilatations in the girders under load.

The dilatations were measured with the deformeters "Izmeron" of the bas $21 \mathrm{~cm}$ and the accuracy $1 / 100 \mathrm{~mm}$.

\section{CONCRETE SHRINKAGE}

The dilatations of concrete shrinkage were measured with the deformeters of the base $21 \mathrm{~cm}$ and of the accuracy $1 / 1000 \mathrm{~mm}$ placed at every side of the unloaded prisms (tab.2) .

\begin{tabular}{|c|c|c|c|c|}
\hline & 28 & 54 & 73 & 150 \\
\hline D61 & 118,129 & 200,492 & 295,998 & 359,186 \\
\hline D62 & 88,456 & 142,329 & 322,488 & 302,576 \\
\hline D63 & 96,412 & 178,893 & 254,378 & 321,926 \\
\hline \hline D71 & 129,835 & 218,121 & 311,728 & 397,818 \\
\hline D72 & 120,056 & 195,232 & 290,896 & 324,396 \\
\hline D73 & 111,298 & 192,350 & 254,198 & 329,193 \\
\hline \hline D82 & 161,632 & 187,903 & 288,281 & 339,183 \\
\hline
\end{tabular}

\begin{tabular}{|c|c|c|c|c|}
\hline & 200 & 250 & 300 & 360 \\
\hline D61 & 351,912 & 379,512 & 388,472 & 400,005 \\
\hline D62 & 299,714 & 321,347 & 339,518 & 350,150 \\
\hline D63 & 322,475 & 334,542 & 352,906 & 348,074 \\
\hline D71 & 381,594 & 399,178 & 408,213 & 418,818 \\
\hline D72 & 341,092 & 354,343 & 376,643 & 380,250 \\
\hline D73 & 352,091 & 356,428 & 356,655 & 346,650 \\
\hline D82 & 341,466 & 358,126 & 370,401 & 374,046 \\
\hline
\end{tabular}

Tab.2 The measured values of the dilation's at the time

The measuring process of the concrete shrinkage in the girders $12 \times 20 \times 250 \mathrm{~cm}$ and loaded at long time load started after 7 days of the girders making and it lasted up to $365^{\text {th }}$ day. Were measured under the constant load at $\mathrm{P}=2 \times 7,81 \mathrm{kN}$.

\section{CONCRETE CREEPING}

The concrete creeping was measured in the girders under the constant load which was applying through so called a single bar on the steel frame (it was purpose constructed for this experiment).

So the girders were under the constant loading throughout the testing. The concrete creeping was measured by the deformeters. The measured dilatations provoked by the concrete creeping in the girders included the dilatations provoked by the concrete shrinkage and they were $25,2 \%$.

The value $11 \%$ of the concrete creeping of the concrete girders presents the difference between the sum $24 \%$ of the concrete shrinkage abtained in the unloaded prisms (fig.5).

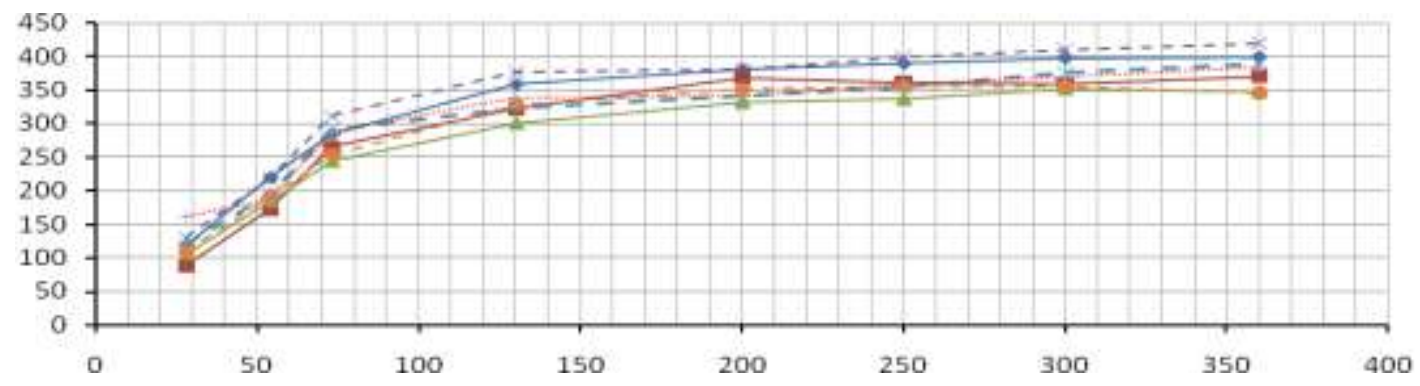

Fig.5 The diagram of the concret schrinkage 
It the concrete creeping in the loaded prisms was measured under long time load at 365 days through the apparatus made for this experiment .

\section{EXPERIMENTAL RESULTS}

- according to my experience concerting the reinforced girders with or without the mineral eool fibers, I can conclude that :

- the concrete shrinkage and creeping were fallowed at the same time on the concrete test girders $(12 \times 20 \times 250 \mathrm{~cm})$ and on the prisms (10x10x20 cm).

- the shrinkage of the concrete was measured on the unloaded prisms with the addition of the mineral wool fibers by the deformeters .

- the dilatations changes caused by the concrete shrinkage and creeping appeared at the same time.

- the stress, in the most stressed fibers decreased 25,2 to throughout 12 months while it increased in the tensed armature as follows: the concrete shrinkage was $11,2 \%$ and the concrete creeping was $14,2 \%$.

- the difference between the calculation and the measured stress in the concrete was 5,66 and the calculated stress were bigger than the measured values.

- the difference between the calculation and the measured stress in the tensed armature was 1,65 and the measured stress values were bigger from the calculated values.

- the calculated stress and the dilatations were defined according to the regulation in the Regulation book BAB '87, $\varepsilon_{\mathrm{b}}=3,5 \%, \varepsilon_{\mathrm{a}}=10 \%$.

- The concrete compressive strength at bending was defined by the value got from the prism loaded by the cross force $\mathrm{P}=8 \mathrm{kN}$ and it was $2,95 \mathrm{MPa}$.

- The $E_{b}=31500 \mathrm{MPa}$ and $\mathrm{E}_{\mathrm{a}}=210000 \mathrm{MPa}$ while analyzing the stress in the concrete and in armature.

- The concrete tensile compressive strength bending was obtained by testing prisms: 10x10x20 $\mathrm{cm}$ with fibers of mineral wool 2,95 $\mathrm{MPa}$ and without fibers of mineral wool 2,5 Mpa .

- The calculated strem the measured stress and stress coincided with this one.

\section{CONCLUSION}

The aim of this paper is to investigate the effect of fibers mineral wool on behavior of reinforced concrete elements tensil compressive strength bending by the transversal forces.

\section{REFERENCES}

[1] A Study on the Reinforced Fibrous Concrete Elements Subjected to Uniaxial Tensile Loading, KSCE Journal of Civil Engineering 14(4):547-556 • July 2010 with 101 Reads, DOI: 10.1007/s12205010-0547-0 .

[2]Sukumar, Aiswarya, and Elson John. "Fiber Addition and Its Effect on Concrete Strength." International Journal of Innovative Research in Advanced Engineering (IJIRAE) ISSN (2014): 2349-2163.

[3]Ravikumar, C. Selin, V. Ramasamy, and T. S. Thandavamoorthy. "Effect of Fibers In Concrete Composites." International Journal of Applied Engineering Research 10.1 (2015): 419-430.

[4]A Study on the Reinforced Fibrous Concrete Elements Subjected to Uniaxial Tensile Loading, KSCE Journal of Civil Engineering 14(4):547-556 . July 2010 with 101 Reads, DOI: 10.1007/s12205010-0547-0 .

[5]Sahoo, Dipti Ranjan, Apekshit Solanki, and Abhimanyu Kumar. "Influence of steel and polypropylene fibers on flexural behavior of RC beams." Journal of Materials in Civil Engineering 27.8 (2014): 04014232.

[6]Flexural Behavior of RC Beams Externally Strengthened with CFRP Composites Exposed to Severe Environment Conditions Rajai Z. AlRousan* and Mohsen A. Issa**, KSCE Journal of Civil Engineering (0000) 00(0):1-10 Copyright (C) 2016 Korean Society of Civil Engineers , DOI 10.1007/s12205-016-0570-x .

First Author. "The Testing of The Tensil Strenght Concrete At Bending ." International Journal of Engineering Research and Applications (IJERA) 7.7 (2017): 72-75. 